\title{
Proximal Iliac Artery Stenosis in Allograft Renal Transplant, a Diagnostic beyond Echo-Doppler, Treatment Approach
}

\author{
Douze Makenzi' ${ }^{1}$, Agustin Carreno', Diego Catarovich'2, Hourmant Marie Yvonne'2, Praile Martin ${ }^{3}$, \\ Alberto Carero', Sanchez De la Nieta1, Maiberi Maldonado', Antonio Pinar'1, Makhoul Martin ${ }^{3}$, \\ Mond Victoria ${ }^{3}$
}

${ }^{1}$ General Hospital of Ciudad Real, Ciudad Real, Spain

${ }^{2}$ Centre Hospitalier Universitaire de Nantes, Nantes, France

${ }^{3}$ Centre Hospitalier de Mouscron, Mouscron, Belgium

Email: douzemakensie@yahoo.fr

How to cite this paper: Makenzi, D., Carreno, A., Catarovich, D., Yvonne, H.M., Martin, P., Carero, A., De la Nieta, S., Maldonado, M., Pinar, A., Martin, M. and Victoria, M. (2021) Proximal Iliac Artery Stenosis in Allograft Renal Transplant, a Diagnostic beyond Echo-Doppler, Treatment Approach. Open Journal of Nephrology, 11, 295-303.

https://doi.org/10.4236/ojneph.2021.113024

Received: May 15, 2021

Accepted: July 10, 2021

Published: July 13, 2021

Copyright $\odot 2021$ by author(s) and Scientific Research Publishing Inc. This work is licensed under the Creative Commons Attribution International License (CC BY 4.0).

http://creativecommons.org/licenses/by/4.0/ (c) (i) Open Access

\begin{abstract}
Background: Transplant Renal Artery Stenosis (TRAS) is a well-known vascular complication after a kidney transplant. It is associated with premature renal failure, uncontrolled hypertension, and allograft loss. However, Proximal Iliac Artery Stenosis to a Kidney Transplant (Prox-TRAS) is an uncommon cause of vascular graft complication leading to acute renal failure and refractory hypertension with a less incidence around and only a few cases reports have been described in the medical literature. Methods: We reviewed the medical record of kidney transplant recipients of the General Hospital of Ciudad Real, Spain, from March 2008 to March 2019. We identified all cases (260) with the diagnosis of renal vascular hypertension by imaging studies. Of those 260 renal vascular stenoses, five (5) were diagnosed with proximal iliac artery stenosis through Angio-CT and arteriography. We performed an analysis of clinical parameters and evolution. Results: Prox-TRAS was diagnosed in 5 of the 260 patients who presented acute or progressive allograft dysfunction with refractory hypertension, with an incidence rate of $1.4 \%$. In 4 of them $(1.1 \%)$, we had to resort to another imaging test, angio-CT, arteriography, as the echo-doppler was unable to identify the abnormalities. Hypertension was a constant finding along with impaired renal function (100\%); with respect to Prox-TRAS, its onset was later (12 - 60 months) after transplantation. An increase in TA ( $140 \pm 10$ and $80.7 \pm 7$ to $160 \pm 18$ and $85 \pm 7 \mathrm{mmHg}, \mathrm{p}-0.009)$ was observed. There was an increase in the use of hypotensive drugs $(2.1 \pm$ 1.1 and $4.3 \pm 1, \mathrm{p}-0.003)$. Similarly, in all cases, a worsening of basal creatinine from 0.9 to $0.1 \pm$ to $1.2 \pm(\mathrm{P} \times 0.004)$ was also observed. Prox-TRAS was
\end{abstract}


a cause of the increase in both creatinine and TA $(140 \pm 10$ and $80.7 \pm 7$ to $160 \pm 18$ and $85 \pm 7 \mathrm{mmHg}, \mathrm{P} 0.009)$. All cases were treated by Percutaneous transluminal angioplasty with stent placement, $\mathrm{N}=5$. In the follow-up, improvement was obtained from the claudication clinic as well as renal function and blood pressure, CRB (from $2.7 \pm 1.4$ to $1.8 \pm 0.4 \mathrm{mg} / \mathrm{dL}, \mathrm{P}-0.02$ ) and TA $(160 \pm 18 / 85 \pm 7 \mathrm{mmHg}$ at $138 \pm 7 / 82 \pm 9, \mathrm{p} 0.018)$. Kidney function, blood pressure remained unchanged during follow-up (130 \pm 36 months). Conclusion: Through these cases review, we propose highlighting the importance of extending imaging studies to the iliac artery of the kidney graft in case of high suspected renal vascular hypertension; showing the role and safety of angioplasty as a reasonable and effective treatment in the identified cases. We assessed the possibility of the limited role of Duplex Sonography (DS) regarding clinical and angiographic. PTA is the appropriate initial treatment of Prox-TRAS, with low morbidity and mortality rates, achieving improvement of graft function and amelioration of hypertension.

\section{Keywords}

Acute Kidney Injury, Hypertension Renal Transplant Renovascular Disease, Chronic Kidney Disease

\section{Introduction}

Post-Transplant Renal Artery Stenosis (TRAS) is a well-identified vascular complication after kidney transplant; it is associated with premature kidney failure, uncontrolled hypertension, and allograft loss. TRAS incidence reported vary in different series, ranged from $1 \%$ to $12 \%$, these discrepancies traduce the lake of homogenous criteria used to establish the diagnosis and the presence of asymptomatic lesions [1] [2] [3]. Our main interest in this paper is about the so-called proximal-TRAS (pro-TRAS) id stenosis close to the iliac artery. However, few case reports have described the clinical settings, outcome, and treatment in patients with Prox-TRAS. Data suggests that the incidence for Prox-TRAS is around $2.4 \%$ [4] [5] [6] [7] [8]. Many factors can lead to this anatomic abnormality, such as chronic rejection, long renal artery compression, kinking, and atherosclerotic disease [9]. Furthermore, due to the increased acceptance of elderly patients for kidney transplantation, it's evident to expect an augmentation number of patients with Peripheral Arterial Occlusive Disease (PAOD). Therefore, although the present study is retrospective, we emphasize the role of extended image investigations other than Echo-Doppler (ED) criteria for early diagnosis of Prox-TRAS, and we assess non-invasive follow-up base in clinical and laboratory findings before and after treatment with Percutaneous Transluminal Angioplasty (PTA), Stenting (PTAS).

\section{Materials and Methods}

We reviewed the medical record of kidney transplant recipients of the General 
Hospital of Ciudad Real, Spain, from March 2008 to March 2019; we identified and selected all cases (260) with the diagnosis of renal vascular hypertension by imaging studies. Of those 260 (174 men for 86 women aged between 27 to 67 years old, mean 47 years renal vascular stenosis, five (4 men and one woman) were diagnosed with proximal iliac artery stenosis Angio-CT and arteriography. To vascular risk factors, hypertension was present in all patients $5 / 5$, diabetes in $3 / 5$, lipid hyperlipidemia in $5 / 5$, smoking in $2 / 5$, hyperuricemia in $2 / 5$. The period range in dialysis previous to the TXP was between 1 to 12 years. The pre-transplantation evaluation identified in all patients some degree of a preexisting renovascular disease. The average time between transplantation and renal function deterioration or hypertension ranged from 12 to 60 months. All patients underwent Doppler-sonography evaluation using 2- to 5- $\mathrm{MHz}$ transducers color software. Peak systolic velocities (V max) within the graft arteries were measured under continuous correction of the Doppler beam angle. Arterial stenosis was identified according to the fallowing diagnostic protocol. Technical examination encompasses measurement velocities within interlobar arteries of the upper pole, midportion, and lower pole of the kidney. After calculation parameters of peak-systolic $\left(V_{\max }\right)$ and end-diastolic $\left(V_{\min }\right) V_{\text {mean }}$ from the area under the curve of one pulse cycle. The Persistence Index (PI) was calculated based on the doppler waveform according to the formula.

$$
\mathrm{PI}=\frac{\left(V_{\mathrm{max}}-V_{\min }\right)}{V_{\text {Mean }}}
$$

We take into consideration an average of three calculations of PIs over time to give a mean value. Further, peak-systolic velocities within the graft arteries were measured under continuous correction of the Doppler beam angle.

TRAS was suspected of an increase of $V_{\max }>150 \%$ within the stenosis compared to the pre-or Post-stenotic flow velocity. Therefore, Prox-TRAS was assumed in the case of: pulsus parvus waveform (slow-rising), high systolic peak velocity $\left(V_{\max }>200 \mathrm{~cm} / \mathrm{s}\right.$ ) within the aortoiliac region, and if the flow curve's triphasic form was lost distal to the anastomosis with the transplant artery, decreased (interlobar) renal arterial resistive index (RI): $<0.55$.

Among patients with Pro-TRAS diagnosis, one was identified using the Ultrasonography echo-doppler method (Figure 1). The others 5 patients presented with persistent hypertension $(161 \pm 12$ and $86 \pm 7 \mathrm{mmHg})$, renal dysfunction (eGFR calculated with Cockroft-Gault formula) $22.1 \pm 11.4 \mathrm{ml} / \mathrm{min}$ and 2 patients presented with flash pulmonary edema (Pickering Syndrome). Although ED could not identify renal arterial stenosis, this entity was strongly suspected due to clinical presentation and the absence of any urinary abnormalities'sediment, and Angio-CT was performed.

Angio-CT with three-dimensional images showed caliber changed allow direct visualization of Atheromatous lesions in the iliac arteries, specifically at the proximal segment of the left iliac artery (Figure 2). Arteriography followed by percutaneous transluminal angioplasty (PTA) with tent placement was performed (Figure 2), and clinical parameters and evolution analyzed (Table 1). 


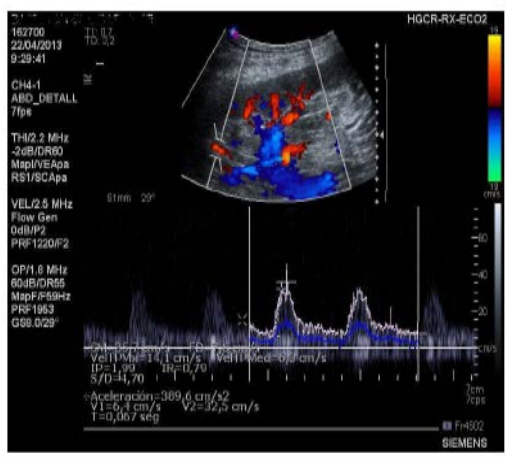

(a)

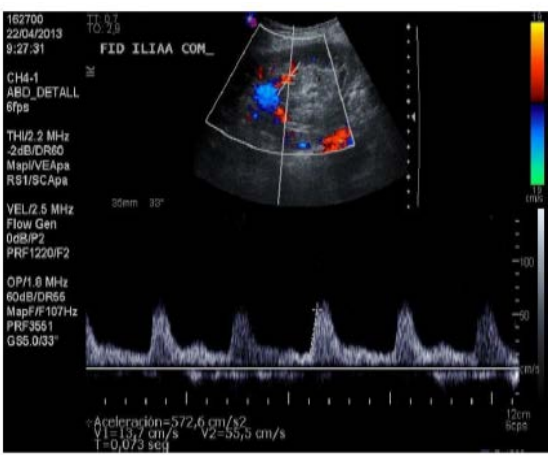

(b)

Figure 1. (a) Echo-doppler findings in a patient with late stenosis of (Prox-TRAS). Flow profile within the external iliac artery distal to the anastomosis of the renal allograft, within the Renal Transplant (RTx) artery, and within the interlobar arteries of the kidney before PTA. (b) Findings of same patients within the external iliac artery distal to the graft anastomosis, within the renal artery, and within the graft after PTA.

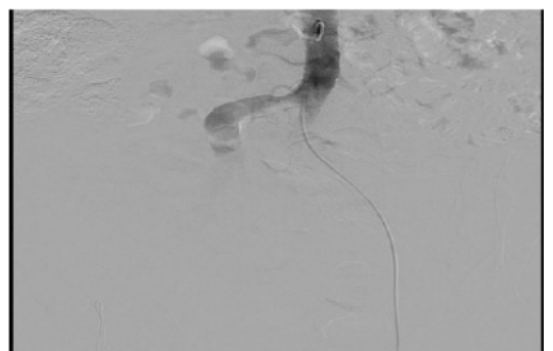

(a)

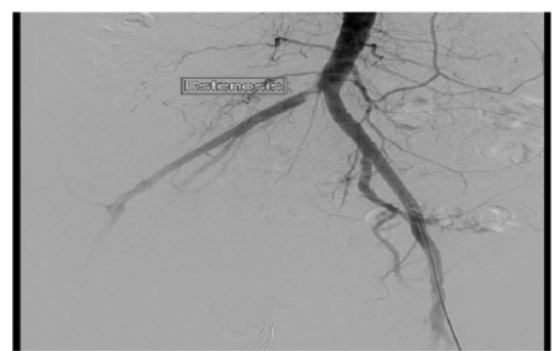

(b)

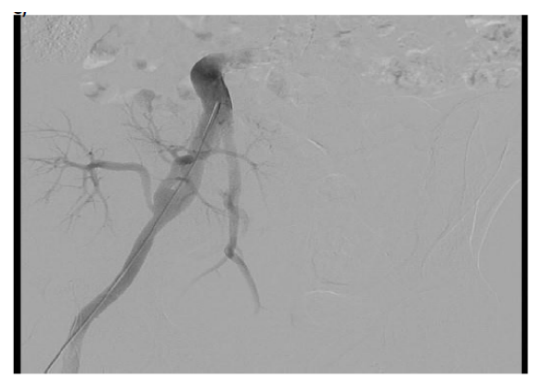

(c)

Figure 2. Arteriography showing kidney allograft recipient with atherosclerotic stenosis of the common iliac artery years after kidney transplantation before $(a, b)$ and after (c) ATP.

Table 1. Hypotensive drugs, renal function, blood pressure, and late onset of Prox-TRAS (n-6) several months after kidney transplantation.

\begin{tabular}{|c|c|c|c|c|c|c|}
\hline & Post transplantation & $\begin{array}{l}\text { At time of diagnosis } \\
\text { of prox-TRAS }\end{array}$ & $\mathrm{p} 1$ & After intervention & $\mathrm{p} 2$ & 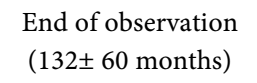 \\
\hline Serum creatinine $(\mathrm{mg} / \mathrm{dL})$ & $0.9 \pm 0.1(n=5)$ & $\begin{array}{l}\quad \pm 1.2(\mathrm{n}=6) \\
\text { (excluding those with } \\
\text { Dialysis dependency) }\end{array}$ & 0.004 & $\begin{array}{c}2.7 \pm 1.4 \text { to } 1.8 \pm 0.4 \\
\text { (excluding patient, } \\
\text { without intervention) }\end{array}$ & 0.02 & $\begin{array}{c}1.9 \pm 0.5(\mathrm{n}=5) \\
\text { (excluding patient } \\
\text { without intervention. }\end{array}$ \\
\hline Systolic blood pressure (mm Hg) & $140 \pm 10(n=5)$ & $160 \pm 18(n=5)$ & 0.009 & $138(\mathrm{n}=11)$ & 0.018 & $136 \pm 9(\mathrm{n}=5)$ \\
\hline Antihypertensive medication (number) & $2.1 \pm 1.1(\mathrm{n}=5)$ & $4.3 \pm 1(n=5)$ & 0.003 & $2.8 \pm 0.8(\mathrm{n}=11)$ & 0.01 & $2.9 \pm 0.6\left(\mathrm{n} \_11\right) \mathrm{NS}$ \\
\hline
\end{tabular}




\section{Results}

From March 2008 to March 2019, Prox-TRAS was diagnosed in 5 of the 260 patients who presented acute or progressive allograft dysfunction with refractory hypertension, with an incidence rate of $1.4 \%$. In 4 of them $(1.1 \%)$ we had to resort to another imaging test arteriography, angio-CT, as the echo-doppler could not identify the abnormality. Hypertension was a constant finding along with impaired renal function (100\%); concerning Prox-TRAS, its onset was later (12 - 60 months) after transplantation (TX). An increase in TA (140 \pm 10 and $80.7 \pm 7$ to $160 \pm 18$ and $85 \pm 7 \mathrm{mmHg}, \mathrm{p}-0.009$ was observed. There was an increase in the use of hypotensive drugs $(2.1 \pm 1.1$ and $4.3 \pm 1, \mathrm{P}-0.003)$. Similarly, in all cases, a worsening of basal creatinine $(\mathrm{Crb})$ from $0.9 \pm 0.1$ a $1.2(\mathrm{P} \times 0.004)$ and renal dysfunction (eGFR calculated with Cockroft-Gault formula) $22.1 \pm$ $11.4 \mathrm{ml} / \mathrm{min}$, was also observed in all cases. Prox-TRAS was a cause of the increase in both creatinine and TA $(140 \pm 10$ and $80.7 \pm 7$ to $160 \pm 18$ and $85 \pm 7$ mmHg, P.0.009). All cases were treated by Percutaneous transluminal angioplasty with stent placement, $\mathrm{N}=5$. In the follow-up, improvement was obtained from the claudication clinic as well as renal function and blood pressure, $\mathrm{Crb}$ (from $2.7 \pm 1.4$ to $1.8 \pm 0.4 \mathrm{mg} / \mathrm{dL}, \mathrm{P}-0.02$ ) and $\mathrm{TA} 160 \pm 18 / 85 \pm 7 \mathrm{mmHg}$ at $138 \pm 7 / 82 \pm 9$, P 0.018). Kidney function, blood pressure remained unchanged during follow-up (132 \pm 60 months) (Table 1$)$.

\section{Discussion}

Several factors can cause TRAS, which will depend on the location and the time between transplantation. When stenosis occurs later after transplantation, it most commonly reveals atherosclerotic disease either of the renal transplant artery or the proximal iliac artery [10]. Prox-TRAS is uncommon, but its clinical symptoms are similar to those of TRAS and usually appear later after transplantation in patients with atherosclerotic disease. Additional findings such as renovascular hypertension and ischemic nephropathy are present in patients with stable kidney function. Peripheral arterial obstructive disease of the lower extremity resulting from peripheral artery resistance can also be present as part of a established peripheral artery resistance disease [11] [12] [13].

In Patients who developed refractory hypertension and allograft dysfunction, physical examination can reveal low femoral pulse reduction and an essential reduction of the lower ankle-brachial index on the right side versus the left [14]; this finding suggested stenosis of the right iliac artery, confirmed was obtained later by the angiographic investigation.

The prevalence and incidence of Prox-TRAS tend to increase due to the augmentation of elderly patients for kidney transplantation and the acceptance of older persons to donate organs. Both groups (recipient and donors) of the population are more likely to present atherosclerotic and Peripheral Arterial Occlusive Disease (PAOD). Thus, native aortoiliac branch atherosclerosis or its afterward development close to the graft is to be expected [15]. Early recognition of 
this entity is crucial since it leads to sufficient and rapid treatment of the allograft dysfunction; therefore, follow-up examination should consider vascular problems close to the kidney artery transplant and proximal to the iliac artery. Identifying TRAS's is not always straightforward; it depends upon having a high index of suspicion and choosing an appropriate imaging modality. Accessible and non-invasive tools as Doppler ultrasound imaging can lead to the diagnosis. But it also depends of the operator and requires identification flux dynamic parameters in color doppler of artery stenosis and adequate patient morphology (less sensitive with obese patients). With high suspicion, CT-Angiography or Magnetic Resonance Angiography (MRA) is more susceptible to identify the disease even in less symptomatic clinical presentation; Even though the definitive diagnosis and treatment of significant arterial stenosis is established by arteriography combined with angioplasty and stenting when indicated [16] [17].

Furthermore, in our center, our practice is to assess clinical manifestations of allograft malfunction presented with severe hypertension by angiography procedure independently of the echo-doppler findings. After the treatment of iliac artery stenosis proximal to renal anastomosis, our cohort patient remained with stable kidney function and free from clinic claudication at least 5 years after follow-up patients. Some others advocate upon measurement of plasma renin levels, but it must be interpreted carefully in TRAS since renin hypersecretion from the kidney transplant can be found in rejection without renal artery stenosis [18]. Others propose isotopic scintigraphy before and after a dose of Captopril and a reported sensitivity of $75 \%$ but a specificity of $67 \%$ [19].

Captopril renography has been reported to have high predictive for significant renal artery stenosis [20]. Even if the gold standard for diagnosing TRAS is selective graft arteriography, special caution should be taken for contrast-induced kidney injury and allergic reactions [19] [21].

With the three-dimensional reconstruction of vessels, computed tomography can provide satisfactory images, therefore prevent less arterial contrast infusion [22]. It's essential to highlight no clear evidence of contrast-induced acute kidney failure [23] [24] in transplant recipients. As computer tomography, magnetic resonance imaging can be a useful diagnostic test, with special warning and concerns about systemic nephrogenic fibrosis [25].

Few fortunate centers with the accessibility use carbon dioxide angiography to successfully visualize the stenosis as a preferred imaging technique, as it avoids nephrotoxicity and hypersensitivity reactions [26], but these investigations are expensive and not universally available.

The first line initial therapy is Percutaneous Transluminal Balloon Renal Angioplasty [27] [28] [29] [30]. In over 70\% of cases, this procedure shows either definitive improvement treatment with the progressive withdrawal of at least two or more hypotensive drugs. Furthermore, few series describe recovery of the renal graft function in some patients who end up with dialysis requirement [29] [30]. In our small series number these improvements were observed in all (100\%) of our patient's follow up. 
The initial interventional procedure of choice for high-grade renal artery stenosis is Patients with TRAS and Prox-TRAS is percutaneous transluminal angioplasty, in case of failure of this procedure, surgical revascularization is then indicated.

\section{Conclusion}

Stenotic artery lesions in allograft Renal Transplant more often occur close to the anastomosis, and it is a well-recognized vascular allograft abnormality. It is also essential to know that stretch of an artery branch can also take place in more proximally to the aortoiliac segment. The objective of this article is to enhance clinicians' experiences on the identification of rare cases of vascular kidney graft dysfunction. In the presence of an acute onset of refractory hypertension, a late deterioration of renal graft function without significant urinary sediment alterations, or any others identified etiology; we consider it advisable to insist the investigation on others imaging tests other than echo-doppler (Angio-TAC contrast-enhanced magnetic resonance angiography, Carbon dioxide angiography). When PTA indicated it should be performed since the overall benefice over the risk of this procedure, considering its relatively low invasiveness. Prompt diagnosis and immediate treatment intervention are of major significance in the prognostic and recuperation of the kidney graft function. This review highlights that PTA is a reliable therapeutic procedure with a high clinical success rate, lasting therapeutic response. Those results are from more cases independent of the topography of stenosis anatomy from the iliac to the renal artery of the kidney transplant.

\section{Conflicts of Interest}

The authors declare no conflicts of interest regarding the publication of this paper.

\section{References}

[1] Roberts, J.P., Asher, N.L., Fryd, D.S., Hunter, D.W., Dunn, D.L., Payne, W.D., et al. (1989) Transplant Renal Artery Stenosis. Transplantation, 48, 580-583.

[2] Sankari, B.R., Geisinger, M. and Zelch, M. (1996) Post-Transplant Renal Artery Stenosis: Impact of Therapy on Long-Term Kidney Function and Blood Pressure control. Journal of Urology, 155, 1860-1864. https://doi.org/10.1016/S0022-5347(01)66030-0

[3] Wong, W., Fynn, S.P., Higgins, R.M., Walters, H., Evans, S., Deane, C., et al. (1996) Transplant Renal Artery Stenosis in 77 Patients-Does It Have an Immunological Cause? Transplantation, 61, 215-219. https://doi.org/10.1097/00007890-199601270-00009

[4] Gossmann, J., Liermann, D., Scheuermann, E.H. and Lenz, T. (1997) Curable Hypertensive Renal Failure Due to Iliac Artery Stenosis in a Kidney Transplant Recipient. Nephrology Dialysis Transplantation, 12, 596-598. https://doi.org/10.1093/ndt/12.3.596

[5] Mathur, V., Kerlan, K., Melzer, J., Tomlanovich, S.J. and Amend, W.J. (1998) Acute 
Renal Allograft Dysfunction Secondary to Suprarenal Arterial Stenosis: A Case Series and Review of the Literature. Clinical Transplantation, 12, 333-342.

[6] Humar, A., Grubbs, B., Zapzalka, D., Nazarian, W., Hunter, D. and Matas, A. (1998) Isolated Iliac Artery Stenosis as a Cause of Kidney Graft Dysfunction Post-Transplant. Clinical Transplantation, 12, 406-408.

[7] Koushik, R.S., Matas, A.J. and Rosenberg, M.E. (2000) Iliac Artery Stenosis Masquerading as Diuretic Resistant Congestive Heart Failure. Clinical Transplantation, 14, 11-13. https://doi.org/10.1034/j.1399-0012.2000.140103.x

[8] Aslam, S., Salifu, M.O., Ghali, H., Markell, M.S. and Friedman, E.A. (2001) Common Iliac Artery Stenosis Presenting as Renal Allograft Dysfunction in Two Diabetic Recipients. Transplantation, 71, 814-817.

https://doi.org/10.1097/00007890-200103270-00022

[9] Bruno, S., Remuzzi, G. and Ruggenenti, P. (2004) Transplant Renal Artery Stenosis. Journal of the American Society of Nephrology, 15, 134-141. https://doi.org/10.1097/01.ASN.0000099379.61001.F8

[10] Messerli, F.H., Bangalore, S., Makani, H., Rimoldi, S.F., Allemann, Y., White, C.J., et al. (2011) Flash Pulmonary Oedema and Bilateral Renal Artery Stenosis: The Pickering Syndrome. European Heart Journal, 32, 2231-2235. https://doi.org/10.1093/eurheartj/ehr056

[11] Safa, J., Nezami, N., Tarzamni, M.K., Zarforooshan, S., Rahimi-Ardabili, B. and Bohlouli, A. (2009) Post-Transplant Urological and Vascular Complications. Saudi Journal of Kidney Diseases and Transplantation, 20, 867-871.

[12] Jordan, M., Cook, G.T. and Cardella, C.J. (1982) Ten Years of Experience with Vascular Complications in Renal Transplantation. Journal of Urology, 128, 689-692. https://doi.org/10.1016/S0022-5347(17)53136-5

[13] Pappas, P., Zavos, G., Kaza, S., Leonardou, P., Theodoropoulou, E., Bokos, J., et al. (2008) Angioplasty and Stenting of Arterial Stenosis Affecting Renal Transplant Function. Transplantation Proceedings, 40, 1391-1396.

https://doi.org/10.1016/j.transproceed.2008.04.016

[14] Humar, A., Grubbs, B., Zapzalka, D., Nazarian, W., Hunter, D. and Matas, A. (1998) Isolated Iliac Artery Stenosis as Causes of Kidney Graft Dysfunction Post-Transplant. Clinical Transplantation, 12, 406-408.

[15] Moss, A., Najarian, J.S., Sutherland, D.E., Payne, W.D., Gruessner, R.W., Humar, A., et al. (2000) 5,000 Kidney Transplants-A Single-Center Experience. Clinical Transplants, 24, 159-171.

[16] Hedegard, W., Saad, W.E. and Davies, M.G. (2009) Management of Vascular and Nonvascular Complications after Renal Transplantation. Techniques in Vascular and Interventional Radiology, 12, 240-262. https://doi.org/10.1053/j.tvir.2009.09.006

[17] Ridgway, D., White, S.A., Nixon, M., Carr, S., Blanchard, K. and Nicholson, M.L. (2006) Primary Endoluminal Stenting of Transplant Renal Artery Stenosis from Cadaver and Non-heart-Beating Donor Kidneys. Clinical Transplantation, 20, 394-400. https://doi.org/10.1111/j.1399-0012.2006.00499.x

[18] Perico, N., Ruggenenti, P., Gaspari, F., Mosconi, L., Benigni, A., Amuchastegui, C.S., et al. (1992) Daily Renal Hypoperfusion Induced by Cyclosporine in Patients with Renal Transplantation. Transplantation, 54, 56-60.

https://doi.org/10.1097/00007890-199207000-00009

[19] Hall, K.A., Wong, R.W., Hunter, G.C., Camazine, B.M., Rappaport, W.A., Smyth, S.H., Bull, D.A., Mcintyre, K.E., Bernhard, V.M. and Misiorwski, R.L. (1992) Con- 
trast-Induced Nephrotoxicity: The Effects of Vasodilator Therapy. Journal of Surgical Research, 53, 317-320. https://doi.org/10.1016/0022-4804(92)90054-4

[20] Shamlou, K.K., Drane, W.E., Hawkins, I.F. and Fennell, R.S. (1994) Captopril Renogram and the Hypertensive Renal Transplantation Patient: A Predictive Test of Therapeutic Outcome. Radiology, 190, 153-159.

https://doi.org/10.1148/radiology.190.1.8259396

[21] Martin-Paredero, V., Dixon, S.M., Baker, J.D., Takiff, H., Gomes, A.S., Busuttil, R.W. and Moore, W.S. (1983) Risk of Renal Failure after Major Arteriography. Archives of Surgery, 118, 1417-1420.

https://doi.org/10.1001/archsurg.1983.01390120045012

[22] Rubin, G.D., Dake, M.D., Napel, S.A., Mcdonnell, C.H. and Jeffrey JR., R.B. (1993) Three-Dimensional Spiral CT Angiography of the Abdomen. Initial Clinical Experience. Radiology, 186, 147-152. https://doi.org/10.1148/radiology.186.1.8416556

[23] Benoit, G., Hiesse C., Icard, P., Bensadoun, H., Bellamy, J., Charpentier, B., Jardin, A. and Fries, D. (1987) Treatment of Renal Artery Stenosis after Renal Transplantation. Transplantation Proceedings, 19, 3600-3601.

[24] Hessel, S.J., Adams, D.F. and Abrams, H.L. (1981) Complications of Angiography. Radiology, 138, 273-281. https://doi.org/10.1148/radiology.138.2.7455105

[25] Lewin, J.S., Laub, G. and Hausmann, R. (1991) Three-Dimensional Time-of-Fight MR Angiography: Applications in the Abdomen and Thorax. Radiology, 179, 261-264. https://doi.org/10.1148/radiology.179.1.2006288

[26] Kuo, P.C., Petersen, J., Semba, C., Alfrey, E.J. and Dafoe, D.C. (1996) $\mathrm{CO}_{2}$ Angiography: A Technique for Vascular Imaging in Renal Allograft Dysfunction. Transplantation, 61, 652-654. https://doi.org/10.1097/00007890-199602270-00023

[27] Fauchald, P., Vatne, K., Paulsen, D., Brodahl, U., Sodal, G., Holdaas, H., Berg, K.J. and Flatmark, A. (1987) Long Term Clinical Results of Percutaneous Transluminal Angioplasty in Transplant Renal Artery Stenosis. Nephrology Dialysis Transplantation, 7, 256-259. https://doi.org/10.1093/oxfordjournals.ndt.a092116

[28] Sniderman, K.W., Sprayregen, S., Sos, T.A., Saddekni, S., Hilton, S., Mollenkopf, F., Soberman, R., Cheigh, J.S., Tapis, L., Stubenbord Jr., W., Tellis, V. and Veith, F.J. (1980) Percutaneous Transluminal Dilatation in Renal Transplant Artery Stenosis. Tranplantation, 30, 440-444.

[29] Greenstein, S., Verstanding, A., Mclean, G., Dafoe, D.C., Burke, D.R., Meranze, S.G., Naji, A., Grossman, R.A., Perloff, L.J. and Barker, C.F. (1987) Percutaneous Transluminal Angioplasty. Transplantation, 43, 29-32. https://doi.org/10.1097/00007890-198701000-00007

[30] Raynaud, A., Bedrossian, J., Remy, P., Brisser, J.M., Angel, C.Y. and Gaux, J.C. (1986) Percutaneous Transluminal Angioplasty of Renal Transplant Renal Arterial Stenosis. American Journal of Roentgenology, 146, 853-857. https://doi.org/10.2214/ajr.146.4.853 